\title{
Sperm of patients with severe asthenozoospermia show biochemical, molecular and genomic alterations
}

\author{
Oriana Bonanno ${ }^{1}$, Giulietta Romeo ${ }^{2}$, Paola Asero ${ }^{1}$, Franca Maria Pezzino ${ }^{2}$, Roberto Castiglione ${ }^{1}$, \\ Nunziatina Burrello ${ }^{1}$, Giuseppe Sidoti ${ }^{3}$, Giovanni Vanni Frajese ${ }^{4}$, Enzo Vicari ${ }^{1}$ and \\ Rosario D'Agata ${ }^{1}$ \\ ${ }^{1}$ Section of Endocrinology, Andrology and Internal Medicine, Department of Medical and Pediatric Sciences, \\ ${ }^{2}$ Section of Clinic Pathology and Molecular Oncology, Department of Biomedical Sciences, University of Catania, \\ Catania, Italy, ${ }^{3}$ Division of Internal Medicine, Garibaldi Hospital Catania, Catania, Italy and ${ }^{4}$ Endocrinology, \\ Department of Sport Medicine, University of Rome Foro Italico, Rome, Italy \\ Correspondence should be addressed to E Vicari; Email: vicarienzo@email.it
}

\begin{abstract}
The multifactorial pathological condition, that is, severe low sperm motility is a frequent cause of infertility. However, mechanisms underlying the development of this condition are not completely understood. Single abnormalities have been reported in sperm of patients with asthenozoospermia. In this study, we characterized, in 22 normozoospermic men and in 37 patients with asthenozoospermia, biochemical, molecular and genomic abnormalities that frequently occur in sperm of patients with asthenozoospermia. We evaluated a panel of sperm biomarkers that may affect the motility and fertilizing ability of sperm of patients with severe asthenozoospermia. Since reactive oxygen species (ROS) production is involved in the pathogenesis of such sperm abnormalities, we determined the association between ROS production and sperm abnormalities. High percentage of patients with severe asthenozoospermia showed increased basal and stimulated ROS production. Moreover, these patients showed increased mitochondrial DNA (mtDNA) copy number but decreased mtDNA integrity and they were associated with elevated ROS levels. Furthermore, mitochondrial membrane potential was also significantly decreased and again associated with high ROS production in these patients. However, the rate of nuclear DNA fragmentation was increased only in less than one-fifth of these patients.

An important cohort of these patients showed multiple identical biochemical, molecular and genomic abnormalities, which are typical manifestations of oxidative stress. The most frequent association was found in patients with high ROS levels, increased mtDNA copy number and decreased integrity, and low MMP. A smaller cohort of the aforementioned patients also showed nDNA fragmentation. Therefore, patients with asthezoospermia likely present reduced fertilizing potential because of such composed abnormalities.

Reproduction (2016) 152 695-704
\end{abstract}

\section{Introduction}

Low sperm motility (asthenozoospermia) alone or in combination with other sperm abnormalities is a frequent cause of infertility. Common causes of asthenozoospermia are genital tract infections, varicocele, sperm antibody (ASA), metabolic diseases and tail anatomic abnormalities. Most patients with asthenozoospermia are idiopathic. Cellular energy for sperm motility and propulsion is produced through oxidative phosphorylation, in the mitochondria, a major producer of ATP, through the electron transport chain (Bahr \& Engler 1970, St John et al. 2000). Treatment of sperm with extracellular ATP significantly increases their fertilization potential (Rossato et al. 1999). This complex biochemical and molecular mechanism is genetically controlled by mitochondrial DNA (mtDNA) and nuclear DNA (nDNA) (Bruijn et al. 1981). Thus, in addition to other factors (Calogero et al. 1998, Narisawa et al. 2002), genomic integrity of mtDNA and nDNA plays an important role in maintaining good sperm motility. The mitochondria regulate also cell apoptosis by releasing several apoptotic factors (Susin et al. 1999). Many infertile men have fragmented nDNA (Varum et al. 2007).

Several studies support the importance of the mitochondria in maintaining sperm quality and motility; in fact, asthenozoospermia (Folgero et al. 1993) and oligoasthenozoospermia (Lestienne et al. 1997) have been reported in patients with typical mitochondrial diseases characterized by point mutations or multiple deletions in mtDNA. Various large deletions in and fragmentation of mtDNA have been observed in 
sperm with poor sperm quality (Kao et al. 1995, 1998, Song \& Lewis 2008). Moreover, comparison of several polymorphic regions in mtDNA has shown an association between mtDNA haplogroup and asthenozoospermia (Ruiz-Pesini et al. 2000). Additional studies indicate that sperm in abnormal semen samples show quantitative alterations in mtDNA and that sperm of infertile men show increased mtDNA content or copy number (May-Panloup et al. 2003, Song \& Lewis 2008). Diez-Sanchez et al. (2003) showed a clear difference in mtDNA copy number between progressively motile and non-progressively motile sperm. These qualitative and quantitative alterations in abnormal sperm may be because of impaired mitochondrial maintenance or oxidative stress-induced deleterious effects on mtDNA (May-Panloup et al. 2003, Shamsi et al. 2009, Venkatesh et al. 2009). Since nuclear and mitochondrial gene products are dependent on each other, nDNA fragmentation may be a more reliable predictor of impaired sperm motility (Muratori et al. 2000). Causes of nDNA damage are not completely understood. However, several studies suggest that increased intracellular or extracellular reactive oxygen species (ROS) (Aitken \& Curry 2011) and the consequent oxidative stress play a key role in inducing nDNA damage. Sperm contain several ROS substrates such as unsaturated fatty acids, DNA, and proteins and possess limited endogenous antioxidant capacity (Alvarez et al. 1987, Aitken et al. 1989). Therefore, sperm are highly susceptible to oxidative damage, which in turn affects mtDNA and nDNA (Aitken \& De luliis 2010). In addition, loss of mitochondrial membrane potential (MMP) and subsequent decrease in energy production may decrease sperm motility (Marchetti et al. 2004), which are often associated with elevated ROS levels (Wang et al. 2003).

Endogenous ROS production or ROS formed in leucocytes present in semen affect sperm (Whittington \& Ford 1999). Use of recently developed probes against mitochondria-produced ROS has shown that mitochondria are the main source of ROS in sperm (Koppers et al. 2008, Aitken et al. 2012). Once initiated, ROS production becomes a self-perpetuating peroxidation mechanism (Aitken et al. 2012) by generating peroxyl and lipid radicals that perpetuate the chain reaction of lipid peroxidation, a process which is very harmful to sperm (Alvarez et al. 1987, Aitken \& Curry 2011), at biochemical and molecular levels (Agarwal \& Allamanemi 2004) because it damages different substrates, including permanent damage of the axoneme (de Lamirande \& Gagnon 1992, Hughes et al. 2009).

Therefore, this study evaluated a panel of sperm biomarkers that exert detrimental effects on sperm motility in men with severe asthenozoospermia and determined the association of ROS overproduction to these biofunctional sperm alterations. To this end, we performed biochemical, genomic and molecular analyses of sperm collected from patients with high initial percentage of non-progressive motile sperm.

\section{Materials and methods}

\section{Chemicals and reagents}

All chemicals used in this study were purchased from Sigma, unless otherwise specified. Percoll was purchased from Codisan (Milano, Italy), and 5-amino-2,3-dihydro-1,4phthalazinedione (luminol) and dimethyl sulfoxide (DMSO) were purchased from Bouty (Milano, Italy). The 12-myristate, 13-acetate phorbol ester (PMA) was purchased from VWR International (Milano, Italy), and 5,5',6,6'-tetrachloro1, $1^{\prime}, 3,3^{\prime}$-tetraethyl benzimidazolyl carbocyanine iodide (JC-1) dye was purchased from Space Import-Export (Milano, Italy). Annexin V, PI, LPN DNA-Prep Reagent (L DNA-Pr) and Mebstain Apoptosis (Meb-Ap) Kit were purchased from Beckman Coulter (Milano, Italy). DNA isolation kit was purchased from Qiagen, and TOPO TA Cloning (TOPOT-Cl) Kit and AccuPrime Pfx (AcP-Pfx) DNA polymerase were purchased from Invitrogen. iQ SYBR Green Kit was from Thermo Fisher.

\section{Preparation of human sperm}

This study included 37 men recruited from couples who underwent semen analysis at the Andrology Centre of Catania University (EAA Andrology Centre) as a part of their fertility evaluation. As the study was intended to be performed in patients with a high percentage sperm with low motility, semen samples were collected from patients whose sperm showed arbitrary progressive motility $(a+b \leq 20 \%)$ and non-progressive motility (c $>50 \%$ ). Patients included in the study were diagnosed with idiopathic asthenozoospermia, clinical palpable varicocele, inflammation of the accessory sex glands or as overweight following physical examination and history taking. Smokers, patients with known exposure to toxic chemicals, alcohol intake or drug abuse, systemic diseases, and recent hormonal treatment were criteria of exclusion. In addition, the study included 22 healthy men with normal sperm parameters (according to the WHO 2010 guidelines) whose fertility status was unknown and who volunteered to participate in the study. Exclusion criteria for this group were cigarette smoking, history of cryptorchidism and varicocele, known exposure to toxic chemicals and presence of genital inflammation. This study was approved by the Institutional Research Review Board of the University of Catania Medical School, and all subjects provided written informed consent. Semen samples from men in both the study groups were collected in sterile plastic jars through masturbation after 3-5 days of abstinence. Routine semen analysis was performed within $1 \mathrm{~h}$ after ejaculation by using a light microscope to determine conventional sperm parameters (WHO 2010). An aliquot of the semen sample was used for evaluating ROS production. The remaining semen sample was purified by performing Percoll density gradient centrifugation and was used for molecular and genomic analyses. 
Purification of human spermatozoa was achieved using a two-step discontinuous Percoll gradient (90\%/45\%) obtained by diluting isotonic Percoll $(90 \mathrm{~mL}$ Percoll supplemented with $10 \mathrm{~mL}$ of $10 \times$ Ham's F10 (WHO 2010) solution, $370 \mu \mathrm{L}$ sodium lactate syrup, $3 \mathrm{mg}$ sodium pyruvate, $210 \mathrm{mg}$ sodium hydrogen carbonate and $100 \mathrm{mg}$ polyvinyl alcohol) with HEPES-buffered Biggers, Whitten and Whittingham medium (BWW) (Biggers et al. 1971), according to Mitchell et al. (2011). Next, up to $3 \mathrm{~mL}$ liquefied semen was layered on top of each gradient and was centrifuged at $500 \mathrm{~g}$ for $30 \mathrm{~min}$. Sperm pellet obtained from the base of the high-density fraction of the gradient was recovered, washed with $3 \mathrm{~mL}$ BWW and pelleted by centrifugation at $600 \mathrm{~g}$ for $10 \mathrm{~min}$.

The final pellet was suspended in a low volume of BWW and was examined under a light microscope. Generally, no round cells were found. However, samples containing round cells or $>15 \%$ immotile sperms were discarded.

\section{Measurement of ROS production}

Aliquots of $5-10 \times 10^{6}$ sperm were washed with two volumes BWW and were centrifuged at $300 \mathrm{~g}$ for $5 \mathrm{~min}$. Seminal plasma was discarded. ROS production was measured by performing a chemiluminescence assay, as described previously (D'Agata et al. 1990). Briefly, $5 \mu \mathrm{L}$ luminol, which was stored as a $20 \mathrm{mM}$ stock solution in DMSO, and $8 \mu \mathrm{L}$ horseradish peroxidase (1550 IU/mL in PBS), which was added to sensitize the assay (Krausz et al. 1992), were added to $500 \mu \mathrm{L}$ of the washed sperm suspension as probes. Next, the sperm suspension was diluted with $500 \mu \mathrm{L}$ BWW, and basal and stimulated ROS production was determined by measuring chemiluminescence with Bioluminate LB 9500 T luminometer (Berthold Technologies, Bad Wildbad, Germany) in an integrated mode for $10 \mathrm{~min}$. Results are expressed as the number of photons counted per minute $(\mathrm{cpm}) / 10 \times 10^{6}$ sperms.

Basal chemiluminescent signal (basal ROS) was monitored at $37^{\circ} \mathrm{C}$ until its stabilization (approximately 5-10 min). After the system returned to baseline, the sperm suspension in the lumivial was stimulated with $2 \mu \mathrm{L}$ formyl-leucylphenylalanine (FMLP), a polymorphonuclear leucocytespecific chemiluminescent probe (Krausz et al. 1992, 1994), and was monitored for additional $7 \mathrm{~min}$ to determine the magnitude of peak obtained. After the signal returned to baseline, $4 \mu \mathrm{L} 10 \mu \mathrm{M} / \mathrm{L}$ PMA was added to the sperm suspension. PMA increases ROS production by stimulating kinase $C$ in both leucocytes and sperm (Ford 1990), resulting in a sustained increase in the chemiluminescent signal (Krausz et al. 1994).

\section{Flow cytometric analysis}

Flow cytometric analysis was performed using EPICS XL (Beckman Coulter), as reported previously (Perdichizzi et al. 2007). In all, 10,000 events were measured for each sample at a flow rate of 200-300 events/s and were analyzed using SYSTEM II Software, 3.0 Version (Coulter Electronics, Milan, Italy).

\section{Determination of MMP}

The lipophilic cationic fluorescent dye JC-1 was used to differentiate and label mitochondria with high and low membrane potential. Sperm with intact mitochondria show an intense red-orange fluorescence. In contrast, JC-1 treated sperm with low MMP form monomers that show green fluorescence (Troiano et al. 1998).

In this study, MMP was determined by adjusting the density of the sperm suspension at $0.5-1 \times 10^{6} \mathrm{cells} / \mathrm{mL}$ with $500 \mu \mathrm{L}$ phosphate buffer and by incubating the sperm with JC-1 in the darkness at $37^{\circ} \mathrm{C}$ for $10-15 \mathrm{~min}$. JC- 1 was dissolved in DMSO to obtain $1 \mathrm{mg} / \mathrm{mL}$ stock solution. JC-1 $(20 \mu \mathrm{g})$ was diluted in $480 \mu \mathrm{L}$ PBS before adding it to the sperm suspension.

\section{Annexin V/PI assay}

PS externalization was determined by staining sperm with FITC-labelled annexin $\mathrm{V}$ and PI by using a commercial kit (Perdichizzi et al. 2007). Double staining allows the distinction of (a) viable sperm (sperm not stained with annexin $\mathrm{V}$ and PI), (b) sperm in the early stage of apoptosis (PS externalization) (sperm stained with annexin $\mathrm{V}$ but not with $\mathrm{PI}$ ), (c) sperm in the late phase of apoptosis (sperm stained with annexin $\mathrm{V}$ and PI) and (d) necrotic sperm (sperm stained with PI but not with annexin V). Briefly, an aliquot of the semen sample containing $0.5 \times 10^{6} \mathrm{sperm} / \mathrm{mL}$ was resuspended in $500 \mu \mathrm{L}$ binding buffer, was labelled with $1 \mu \mathrm{L}$ annexin V-FITC and $5 \mu \mathrm{L} \mathrm{Pl}$, was incubated in the darkness for 10-15 min and was analyzed immediately. Signals were detected using FL-1 (FITC) and FL-3 (PI) detectors.

\section{PI staining}

The degree of chromatin compaction was evaluated using the sperm PI staining (Perdichizzi et al. 2007).

Briefly, an aliquot containing approximately $1 \times 10^{6} \mathrm{sperm} / \mathrm{mL}$ was incubated with $100 \mu \mathrm{L}$ lysing and permeabilizing reagent in the darkness at room temperature. After $10 \mathrm{~min}, 500 \mu \mathrm{L} \mathrm{L}$ DNA-Pr (containing PI, RNAse type A, NaN salts and stabilizer) was added to the sperm suspension, and the suspension was incubated in the darkness for $30 \mathrm{~min}$.

Sperm with normal chromatin packaging emitted low PI fluorescence because less amount of PI reached the DNA. In contrast, sperm containing endogenous nicks in DNA emitted high fluorescence.

\section{TUNEL assay}

The evaluation of fragmentation of DNA was obtained through the Tunnel assay as reported previously (Perdichizzi et al. 2007). Briefly, the assay was conducted on aliquots of about $1 \times 10^{6}$ washed sperm, which were labelled using the Meb-Ap Kit. To obtain a negative control, deoxynucleotidyl tansferase was omitted from the reaction mixture, and positive control was obtained by pretreating the sperm with $1 \mu \mathrm{g} / \mathrm{mL}$ deoxyribonuclease I, RNAse-free at $37^{\circ} \mathrm{C}$ for $60 \mathrm{~min}$ before labelling. 


\section{Extraction of total DNA}

DNA from the sperm samples of patients and controls was extracted using a DNA isolation kit, according to the manufacturer's instructions. Extracted DNA was quantified using NanoDrop 1000 spectrophotometer (Thermo Scientific) in triplicate.

\section{Long-range PCR for determining mtDNA integrity}

Long-range PCR (long PCR) was performed to amplify approximately half of the mitochondrial genome $(8.7 \mathrm{~kb})$ by using AcP-Pfx DNA polymerase, which is inactive at ambient temperatures and is activated after initial denaturation to determine mtDNA integrity.

Long PCR was performed in a $50-\mu \mathrm{L}$ reaction mixture containing $1 \times$ buffer with dNTPs,

- forward primer (5'-AAGGATCCTCTAGAGCCCACTG TAAAG-3'),

- reverse primer (5'-TTGGATCCAGTGCATACCGCC AAAAG-3'),

- $2.5 \mathrm{U}$ DNA polymerase,

- 200 ng sperm DNA.

Amplification conditions were as follows: initial denaturation at $95^{\circ} \mathrm{C}$ for $2 \mathrm{~min}$, followed by $25-35$ cycles of denaturing $\left(95^{\circ} \mathrm{C}\right.$ for $\left.15 \mathrm{~s}\right)$, annealing $\left(62^{\circ} \mathrm{C}\right.$ for $\left.1 \mathrm{~min}\right)$, and extension step at $68^{\circ} \mathrm{C}$ for $9 \mathrm{~min}$. PCR products obtained were visualized by electrophoresis on $0.8 \%$ agarose gels. DNA extracted from sperm treated with $\mathrm{H}_{2} \mathrm{O}_{2}$ for $1 \mathrm{~h}$ at $37^{\circ} \mathrm{C}$ was used as control. Results of long PCR showed that DNA amplification decreased after $\mathrm{H}_{2} \mathrm{O}_{2}$ treatment.

\section{Determination of mtDNA copy number}

Quantitative PCR (qPCR) was performed to determine the relative copy number of mtDNA, which was calculated using the copy number ratio of mitochondrial gene encoding $16 \mathrm{~S}$ rRNA to nuclear gene encoding glyceraldehyde-3-phosphate dehydrogenase (GAPDH) (Song \& Lewis 2008). To synthesize standard DNA, PCR was performed using 16S RNA primers under the following amplification conditions: the first cycle at $94^{\circ} \mathrm{C}$ for $5 \mathrm{~min} ; 30$ cycles of denaturation at $94^{\circ} \mathrm{C}$ for $1 \mathrm{~min}$, annealing at $58^{\circ} \mathrm{C}$ for $1 \mathrm{~min}$ and extension at $72^{\circ} \mathrm{C}$ for $1 \mathrm{~min}$; and final extension at $72^{\circ} \mathrm{C}$ for $10 \mathrm{~min}$. Before cloning, PCR products obtained were electrophoresed on $1 \%$ agarose gel, which produced a single 150-bp band. The 150-bp fragment was cloned into the PCR 2.1-TOPO vector by using the TOPOT-Cl Kit, was sequenced to confirm the accuracy of the inserted sequence and was used as standard DNA for performing qPCR. Plasmid DNA obtained was quantified using NanoDrop 1000 spectrophotometer was diluted to obtain $1 \times 10^{2}$ to $1 \times 10^{8}$ copies $/ \mu \mathrm{L}$, and was stored in at $-80^{\circ} \mathrm{C}$ in a freezer.

The amount of mtDNA and GAPDH was determined using two primer sets specific to the mitochondrial $16 \mathrm{~S}$ rRNA gene and nuclear GAPDH. The mitochondrial amplification reaction was performed in duplicate with $16 \mathrm{~S}$ rRNA (forward primer 5'-ACTTTGCAAGGAGAGCCAAA-3' and reverse primer 5'-TGGACAACCAGCTATCACCA-3'). Nuclear GAPDH was amplified using forward primer 5'-GGATGATGTTCTGGAAGAGCC-3' and reverse primer 5'-AACAGCCTCAAGATCATCAGC-3'. Primers were included in triplicate along with negative control samples and a range of standards. The qPCR was performed using ABI 7300 (Applied Biosystems) with iQ SYBR Green Kit, according to manufacturer's instructions.

The SYBR green dye binds to double-stranded DNA but not to single-stranded DNA and can be used for monitoring DNA amplification during qPCR (10 ng template; initial denaturation at $95^{\circ} \mathrm{C}$ for $5 \mathrm{~min}$, followed by 40 cycles of denaturation at $95^{\circ} \mathrm{C}$ for $10 \mathrm{~s}$ and annealing at $60^{\circ} \mathrm{C}$ for $30 \mathrm{~s}$ ). Moreover, the dye emits bright fluorescence upon binding to DNA. Melting curve analysis was performed to verify the accuracy and specificity of amplification.

\section{Statistical analysis}

All the variables were initially tested using KolmogorovSmirnov test to determine data normality. Data of normally distributed variables were expressed as mean \pm S.D. and those of non-normally distributed variables were expressed as median and 25-75 percentile. Groups were compared using unpaired Student's t-test and non-parametric test (Mann-Whitney $U$ test) for normal and non-normal distribution, respectively. Correlation analysis among the study variables was performed using Spearman's non-parametric test with untransformed values. For all the statistical tests, differences with $P<0.05$ were considered significant. Difference in deletion frequency was determined using $\chi^{2}$ test.

All analyses were performed using SAS statistical software package version 9.1 (SAS Institute Inc., Cary, NC, USA).

\section{Results}

Median age of controls was 33.3 years (range, 20.1-40.7 years), which was not significantly different from that of patients (26.4 years (range, 22.9-38.1)). As expected, all the parameters of sperm from patients were significantly lower than those of sperm from healthy controls. However, sperm with normal morphology were comparable. Moreover, ejaculates of patients showed high leucocyte infiltration $(P<0.0001$; Table 1$)$. In contrast, ejaculates of only 6 controls $(27.2 \%)$ showed leucocyte contaminations (less than $1 \times 10^{6} / \mathrm{mL}$ ).

\section{Seminal ROS production}

ROS production was measured using the total population of unfractionated cells to determine the overall oxidative status of the ejaculate. Basal ROS production (in 58.3\% samples) and stimulated ROS production (in $70.8 \%$ and $83.3 \%$ samples treated with FMLP and PMA, respectively) were significantly higher $(P<0.0001)$ in patients than in controls (Fig. 1). In all the patients with increased spontaneous, 


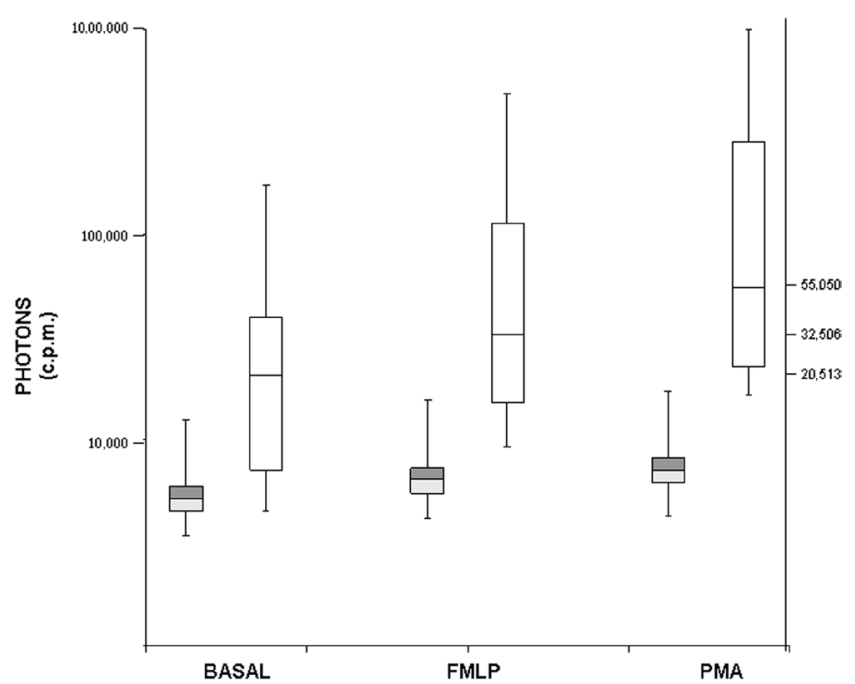

Figure 1 Basal, FMLP-stimulated and PMA-stimulated ROS production in controls and patients (open bars) with asthenozoospermia.

Bars represent median and the 25th and 75th percentiles.

Vertical lines represent range. Vertical axis is in logarithmic scale.

Bars in the right vertical axis indicate medians in patients.

basal level of activity, FMLP- and PMA-stimulated ROS production was higher than the basal ROS production. Consistently, chemiluminescent signals after PMA stimulation were elevated significantly over those after FMLP stimulation $(P<0.001)$. Significant correlation was observed between basal and stimulated ROS production $(r=0.44, P<0.03$ and $r=0.76, P<0.00001$ for FMLP- and PMA-stimulated ROS, respectively) in semen samples of patients with asthenozoospermia. Furthermore, FMLP- $(r=0.5$, $P<0.01)$ and PMA-stimulated ROS production $(r=0.46, P<0.02)$ but not basal ROS production were correlated with leucocyte concentration in the semen samples. Moreover, strong correlation was observed between PMA- and FMLP-stimulated ROS production $(r=0.89, P<0.000002)$, but in three cases production was stimulated by the addition of PMA only, with the response being lower than that with FLMP. However, no correlation was observed between basal as well as stimulated ROS production and sperm parameters or between ROS production and mtDNA copy number or flow cytometric sperm variables, except DNA fragmentation.

\section{Integrity of mtDNA in sperm of patients with asthenozoospermia and controls}

Long PCR amplified an 8.7-kb fragment from the 16-kb mitochondrial genome in all the samples. This $8.7-\mathrm{kb}$ fragment contains several genes encoding subunits of energetic complexes as well as the common deletion types $4.3 \mathrm{~kb}$ and $7.4 \mathrm{~kb}$ in sperm (Song \& Lewis 2008). Figure 2 shows the representative products of long PCR from 2 normozoospermic controls and 2 patients.

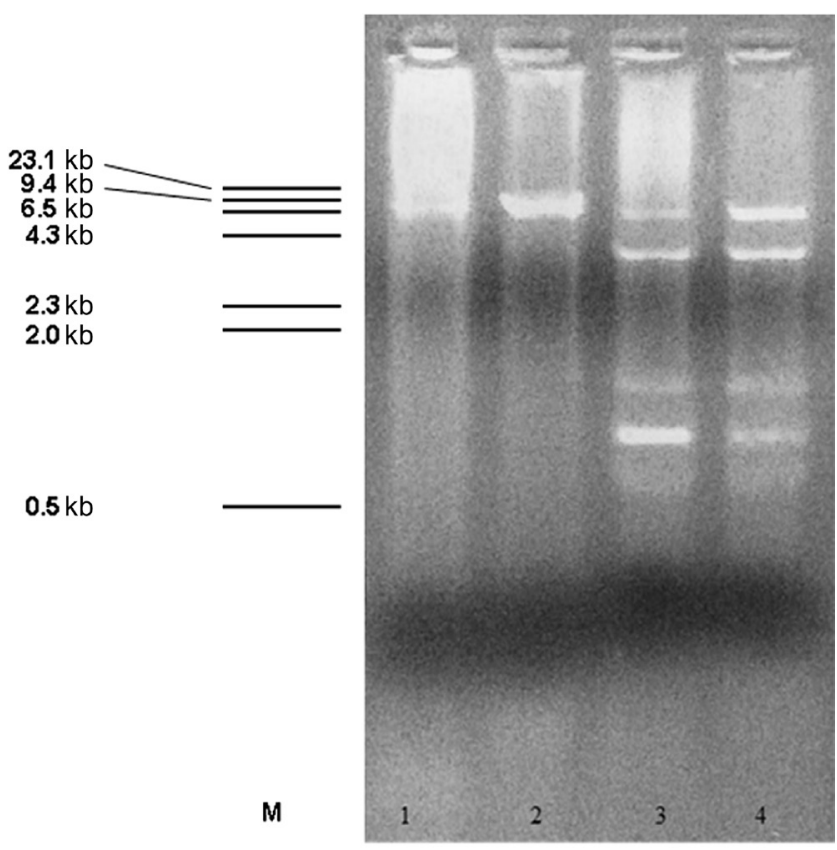

1-2 NORMAL SAMPLES 3-4 ASTENOZOOSPERMIC SAMPLES $M \quad \lambda$ DNA / Hind III

Figure 2 Four representative products of long PCR analysis of human sperm for determining mtDNA integrity. Lanes 1 and 2: results of long PCR of mtDNA of sperm from 2 controls. Lanes 3 and 4: results of long PCR of mtDNA of sperm from two representative patients with asthenozoospermia. Lanes 1 and 2 show a high-intensity $8.7-\mathrm{kb}$ band, which represents full-length wild-type mtDNA, indicating the presence of normal intact mtDNA. Lanes 3 and 4 show low-intensity 8.7-kb bands, indicating the presence of low amount of full-length $\mathrm{mtDNA}$, and smaller bands, indicating deletions in mtDNA. HindIII/K was used as a size marker.

The high intensity of the full-length band indicated the presence of normal intact mtDNA (Fig. 2, lanes 1 and 2). In contrast, the low intensity of full-length mtDNA band indicated poor mtDNA integrity because of low amount of mtDNA, fragmentations and deletions. The results of long PCR showed differences in mtDNA integrity in sperm of controls and patients. Normozoospermic controls showed high intensity of full-length band and did not contain deletions in mtDNA, indicating normal intact mtDNA. In contrast, $36(97.2 \%)$ patients showed multiple deletions in mtDNA (Fig. 2, lanes 3 and 4). This difference in the frequency of deletions in mtDNA between patients and controls was highly significant $(P<0.0001)$. Only 1 patient with asthenozoospermia had intact mtDNA; however, this patient showed high PS externalization and had abnormal chromatin compactness values (results not shown). Moreover, this patient had the highest mtDNA copy number and showed the highest PMA-stimulated ROS production. In addition, this patient showed low progressive sperm motility of $12 \%$, with 1 million leucocytes in the ejaculate. Furthermore, abnormal mtDNA 
was associated with high ROS production in sperm samples of $83.4 \%$ patients.

\section{Alterations in mtDNA copy number in sperm of patients and controls}

The median mtDNA copy number in sperm of patients with asthenozoospermia was 14.8 (percentile, 5.4-29.68; range, 1-61), which was significantly higher than that in controls (median, 5.75 (percentile, 4.72-7.05; range, $1.1-10) ; P<0.006)$. This increase in mtDNA copy number was observed in $45.8 \%$ patients. Moreover, patients with increased mtDNA copy number showed high ROS production.

\section{Integrity of $n D N A$}

Integrity of nDNA, which was measured using the TUNEL assay, was not significantly different between the two study populations (median, $2.4 \%$ (percentile, 1.4-3.2; range $0.5-4.0$ ) vs $2.0 \%$ (percentile, 0.9-5.0; range $0.6-34.6)$ in controls and patients, respectively; Table 1 ). In all, $16.6 \%$ patients showed very high rate of nDNA fragmentation $(>10 \%)$. However, the rates of nDNA fragmentation in the remaining patients were within normal limits or between $4 \%$ and $5.1 \%$. Moreover, the rate of nDNA fragmentation was correlated with basal ROS production in patients $(r=0.48, P<0.016)$.

\section{MMP}

The sperm of only $8(21.6 \%)$ patients showed normal (high) MMP compared with that of controls (mean, $55.3 \% \pm 21.7$ vs $86.1 \% \pm 7.9 ; P<0.0001)$. Low MMP was associated with high ROS production in a high percentage $(78.9 \%)$ of patients.

\section{Other flow cytometric parameters}

No significant differences were observed in percentage viability, PS externalization, late apoptosis, necrosis or abnormal chromatin compactness among the sperm of the two study populations (Table 1). Interestingly, a negative correlation was observed between alive sperm and PS externalization $(r=-0.555, P<0.005)$, late apoptosis $(r=-0.666, P<0.0003)$ and necrotic cell numbers $(r=-0.446, P<0.028)$. In contrast, a positive correlation was observed between PS externalization and late apoptosis $(r=0.555, P<0.0048)$.

\section{Subpopulations of patients with multiple abnormalities in sperm}

Next, we determined whether patients with asthenozoospermia showing abnormal ROS in their ejaculates had multiple identical ROS-associated abnormalities in their sperm. Almost all patients showing low MMP and high ROS production had deletions in the $\mathrm{mtDNA}$ of their sperm, and almost half of these patients $(44.6 \%)$ showed increased mtDNA copy number (cohort a). Moreover, $12.6 \%$ of these patients also showed high rate of nDNA fragmentation (>10\%) (cohort b).

\section{Discussion}

The results of this study provide further evidence that severe asthenozoospermia is associated with various abnormalities in sperm. The sperm of patients with asthenozoospermia showed increased ROS production, mitochondrial and nuclear genomic alterations, and multiple molecular abnormalities. However, the frequency of abnormalities in these different nonconventional biofunctional sperm parameters varied in patients with asthenozoospermia (Fig. 3).

Table 1 Descriptive analysis.

\begin{tabular}{|c|c|c|c|c|c|}
\hline \multirow[b]{2}{*}{ Semen variables } & \multicolumn{2}{|c|}{ Controls $(n=22)$} & \multicolumn{2}{|c|}{ Patients $(n=37)$} & \multirow[b]{2}{*}{$P$ value } \\
\hline & Values & Range & Values & Range & \\
\hline \multicolumn{6}{|l|}{ Cytological } \\
\hline Concentration $\left(\times 10^{6} / \mathrm{mL}\right)^{*}$ & $119.3 \pm 49$ & 39-235 & $69 \pm 33.6$ & $20-150$ & $<0.0002$ \\
\hline Total sperm number $\left(\times 10^{6}\right)^{*}$ & $439.3 \pm 196.5$ & $126-750$ & $214.2 \pm 108.8$ & $60-440$ & $<0.0001$ \\
\hline Progressive motility $(\%)(a+b) *$ & $47.4 \pm 9.1$ & $30-68$ & $11.8 \pm 4.8$ & $2-20$ & $<0.0001$ \\
\hline Nonprogressive motility (\%) (c)* & $22.8 \pm 11.7$ & $5-46$ & $61.5 \pm 6.5$ & $52-72$ & $<0.0001$ \\
\hline Non-motile sperm $(\%)(d)^{*}$ & $30.2 \pm 8.9$ & $14-48$ & $26.6 \pm 6.5$ & $16-42$ & $<0.12$ \\
\hline Normal morphology (\%)* & $21.2 \pm 5.4$ & $10-32$ & $19.8 \pm 7.8$ & $8-40$ & $<0.50$ \\
\hline Leukocytes $\left(\times 10^{6} / \mathrm{mL}\right)^{* *}$ & $0(0-0.4)$ & $0-0.9$ & $1(0.7-1.5)$ & $0.3-7$ & $<0.0001$ \\
\hline \multicolumn{6}{|l|}{ Flow cytometry } \\
\hline Viable sperm* & $73.5 \pm 7.8$ & $60.2-86.1$ & $66.2 \pm 19.9$ & $20.7-93.1$ & $<0.11$ \\
\hline Sperm with PS externalization** & $1.9(1.2-2.6)$ & $0.04-13.8$ & $3.2(1.3-4.9)$ & $0.12-40.3$ & $<0.13$ \\
\hline Sperm in late apoptosis $(\%)^{* *}$ & $6.0(2.0-7.8)$ & $0.1-14.7$ & $7.1(4.4-12.6)$ & $0.1-32.0$ & $<0.23$ \\
\hline Necrotic sperm $(\%)^{* *}$ & $16.0(12.2-23.4)$ & $2.2-30.4$ & $13.7(6.3-20.5)$ & $2.2-54.7$ & $<0.39$ \\
\hline Sperm with DNA fragmentation $(\%)^{* *}$ & $2.4(1.4-3.2)$ & $0.5-4.0$ & $2.0(0.9-5.0)$ & $0.6-34.6$ & $<0.6$ \\
\hline Sperm with high (normal) MMP values (\%)* & $86.1 \pm 7.9$ & $72.2-97.8$ & $55.3 \pm 21.7$ & $15.5-95.8$ & $<0.0001$ \\
\hline Sperm with abnormal chromatin compactness $(\%)^{* *}$ & $15.4(11.4-17.8)$ & 8.4-18.9 & $15.2(11.4-21)$ & $4.3-39.3$ & $<0.57$ \\
\hline
\end{tabular}

*Values expressed as mean \pm S.D.; **Values expressed median (25-75\%). 


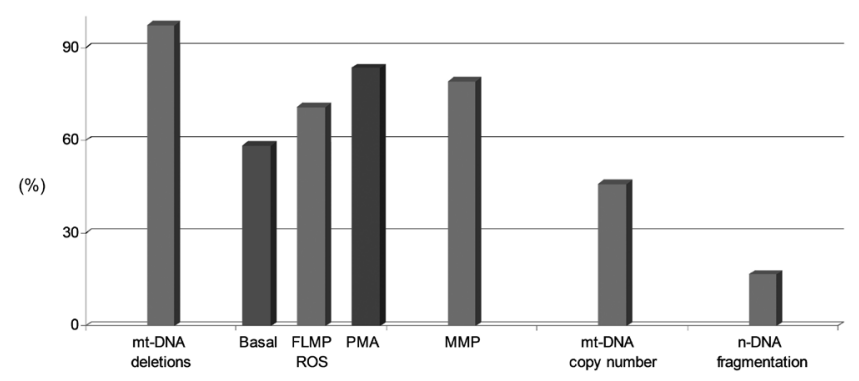

Figure 3 Frequency (\%) of abnormal biochemical, genomic and cytofluorimetric parameters in sperm of patients with asthenozoospermia.

We found that ejaculates of $58.3 \%, 70.8 \%$ and $83.3 \%$ patients, showed increased basal, FMLP-stimulated and PMA-stimulated ROS production, respectively, compared with controls. This result indicated that ROS was overproduced under basal condition irrespective of its source, that is, leucocytes or sperm, which was consistent with the results of Whittington and Ford (1999). As from leucocyte-specific FMLP agonist stimulation, leucocytes, were the main ROS producer in semen samples from a little more than two-thirds of the patients, as elsewhere reported (Krausz et al. 1992, Whittington \& Ford 1999). However, the lack of correlation between ROS levels and sperm motility, a major target of ROS, is unclear. Moreover, the results of previous studies are inconsistent in this regard (Whittington et al. 1999, Kao et al. 2008). Although PMA is the most powerful stimulant for oxidant stimulation by human sperm (Krausz et al. 1992), ROS production in patients after PMA cannot be specifically compartmentalized to some extent to leucocytes or sperm, as the probe is a stimulus for both leucocytes and sperm. However, consistently PMAstimulated ROS production were elevated significantly over those after FMLP, suggesting some amount of ROS production by sperm.

In this study, we observed that almost $50 \%$ patients with severe asthenozoospermia showed significantly increased mtDNA copy number, which was consistent with the results of previous studies that non-progressively motile sperm show increased mtDNA copy number (May-Panloup et al. 2003, Amaral et al. 2007, Song \& Lewis 2008). Recent studies have shown a negative correlation between mtDNA copy number and sperm motility in men with varicocele; moreover, varicocele correction improves sperm motility and decreases mtDNA copy number in these patients (Gabriel et al. 2012). Furthermore, mtDNA copy number increases in men living in hypoxic conditions at high altitudes for 1 year compared with that in men living in plains (Luo et al. 2011). This increase in mtDNA copy number might be induced by elevated oxidative stress (Lee et al. 2000, Liu et al. 2003).

Our results showed decreased mtDNA integrity in almost all sperm samples from patients with asthenozoospermia. These mitochondrial genomic alterations are hallmarks of spermatogenetic dysfunction (Hecht \& Liem 1984, May-Panloup et al. 2003, Song \& Lewis 2008) and severely alter mitochondrial function in abnormal sperm. Genomic alterations were also observed in nDNA; however, the frequency of alterations in nDNA was lower than that in mtDNA. The rate of nDNA fragmentation was not significantly different between controls and patients with asthenozoospermia. However, a small percentage of patients with asthenozoospermia showed high rate of nDNA fragmentation (>10\%). Furthermore, nDNA fragmentation was correlated with basal ROS production, which was consistent with what was reported previously (Aitken et al. 2010). This finding was also consistent with the notion that nDNA fragmentation is often associated with oxidative stress (De luliis et al. 2009). Oxidative stress or ROS production in the mitochondria induces breaks in nDNA (Wang et al. 2003, Aitken \& De luliis 2010). However, mtDNA is more susceptible to the harmful effects of excess ROS production than nDNA (Yakes \& Van Houten 1997, Sawyer et al. 2003). This may be one of the reasons for the higher incidence of abnormalities in mtDNA than in nDNA in patients with asthenozoospermia. Thus, mitochondrial dysfunction may be involved in the pathogenesis of asthenozoospermia in these men. Men with multiple mutations and large deletions in mtDNA showed severe phenotypic defect (Kao et al. 1995, St John et al. 1997, Salehi et al. 2006).

A significantly lower number of sperm of patients with severe asthenozoospermia had normal (high) MMP values as further expression of mitochondrial dysfunction. In fact, only one-fifth of patients with asthenozoospermia had normal MMP values. MMP is a good predictor of sperm quality. Such cell abnormality will result in less energy production for sperm function and motility. Sperm with high MMP values have intact acrosome, high fertilizing capacity, and normal motility and morphology. In contrast, sperm with low MMP values are of low quality and are associated with low IVF rates (Kasai et al. 2002, Marchetti et al. 2004). This is in turn correlated with ROS production (Wang et al. 2003). Dysruption of MMP may occur during early stages of apoptosis in germ cells (Erkkilä et al. 1999) and thus before the induction of nDNA damage in sperm.

Other flow cytometric parameters were not significantly different between patients with asthenozoospermia and normozoospermic controls. Sperm vitality is a good predictor of gamete quality. An inverse correlation was observed between sperm viability and signs of cell apoptosis, such as PS externalization, early and late stages of apoptosis, necrosis and chromatin compactness. This has important clinical implications in that the selection of good quality sperm for ICSI conventionally focuses on mobile and consequently 
viable sperm. Furthermore, positive correlation was observed between PS externalization and late apoptosis, indicating that PS externalization promoted the entry of sperm into the senescence phase, followed by apoptosis and death.

These abnormalities in sperm of patients with severe asthenozoospermia are typical manifestations of ROS-induced damage and are based on a continuum of decreased sperm motility; decreased MMP; decreased mtDNA integrity; increased mtDNA copy number; PS externalization; caspase activation; oxidative nDNA damage, including nDNA fragmentation; late apoptosis; and death. The final damaging consequences on sperm of such exposure depend on the capacity of sperm of these men to withstand oxidative stressor, possibly compounded by a compromised total antioxidant capacity in their seminal fluid (Pasqualotto et al. 2000, Kao et al. 2008). ROS-induced cellular damage also depends on whether ROS production is extracellular (leucocytes) or intracellular (sperm). Extracellular ROS production exerts less damage on nDNA (Henkel et al. 2005). In addition, time and site of ROS exposure, oxidants produced by morphologically poor sperm and other round cells are also important determinants of the degree of severity of ROS-induced cellular damage (Henkel et al. 2005). Therefore, as the generation of these reactive free radicals overwhelms the defence system, this induces oxidative stress, which is characterized by a cascade of cellular damage (Aitken et al. 2010). This may be the reason why only a subpopulation of patients with asthenozoospermia showed increased nDNA fragmentation, which is caused by prolonged exposure to ROS (Aitken et al. 2010). Basal ROS status in the ejaculates of our patients correlates with nDNA damage observed, thus supporting the role of ROS in inducing nDNA alterations. However, these multiple abnormalities observed in sperm of patients with asthenozoospermia may also result from deranged spermatogenesis and then aborted apoptosis (Sakkas et al. 2003).

The general findings of this study are consistent with the hypothesis that sperm of patients with asthenozoospermia have several biochemical, molecular, genomic and functional abnormalities, which may decrease their fertilization potential (Tesarik et al. 2002, Zidi-Jrah et al. 2016). This was also observed in patients with asthenozoospermia included in this study. During follow-up, sperm of 2 patients in subgroup b could not lead to pregnancy after as many as 3 ICSI attempts. In contrast, sperm of 1 patient who had low MMP as the only abnormality led to pregnancy during the first ICSI attempt (results not shown). We observed that patients with this pathological condition could be subgrouped according to the presence of only 1 or more cellular abnormalities, with high ROS production, increased mtDNA deletions and copy number, and reduced MMP being the most common associated abnormalities. Rate of nDNA fragmentation was high only in less than one-fifth of the patients with asthenozoospermia. As time elapses and the cause persists, the current picture might get worse in the absence of any treatment. No robust clinical implications can be drawn from the results of this study because the study included limited number of patients. However, the present findings strengthen the association of high frequency biochemical and biofunctional sperm alterations in patients with severe asthenozoospermia, and emphasize evaluating male factor by sperm function tests to determine hidden anomalies, which may better define the fertility status in vivo and in vitro.

To our knowledge, this is the first study to examine, all together, biochemical, functional, molecular and genomic abnormalities in sperm of patients with asthenozoospermia. These abnormalities make up an evolutionary spectrum of progressive alterations in the presence of oxidative free radical offense, whose final result will be either survival or senescence and then death, eventually going through several intermediate steps. Our results further indicate that sperm of infertile patients with severe asthenozoospermia who are candidates for ICSI may harbour cellular abnormalities, which may jeopardize oocyte fertilization and embryonic development depending on the severity of these abnormalities.

\section{Declaration of interest}

The authors declare that they do not have any conflicts of interest that could prejudice the impartiality of the reported research.

\section{Funding}

This research did not receive any grant from any funding agency in the public, commercial or not-for-profit sector.

\section{Authors' contribution statement}

$\mathrm{R} D$ designed the study, analyzed and interpreted the data, and drafted the manuscript. O B, GR, PA, FM P and N B performed some analyses. O B obtained the data for her PhD thesis. E $\mathrm{V}$ performed clinical evaluation of patients and designed the study. R C and G S organized and revised the manuscript. F G V collaborated in the drafting of the manuscript. E V and $\mathrm{R} D$ contributed equally in the study.

\section{Acknowledgements}

The authors acknowledge the active collaboration of technicians of the Andrology Center for helping in selecting asthenozoospermic samples. 


\section{References}

Agarwal A \& Allamanemi SS 2004 Oxidant and antioxidant in human fertility. Middle East Fertility Society Journal 9 187-197.

Aitken RJ, Clarkson JS \& Fishel S 1989 Generation of reactive oxygen species, lipid peroxidation, and human sperm function. Biology of Reproduction 41 183-197. (doi:10.1095/biolreprod41.1.183)

Aitken RJ \& Curry BJ 2011 Redox regulation of human sperm function: from the physiological control of sperm capacitation to the etiology of infertility and DNA damage in the germ line. Antioxidants and Redox Signaling 14 367-381. (doi:10.1089/ars.2010.3186)

Aitken RJ \& De luliis GN 2010 On the possible origins of DNA damage in human spermatozoa. Molecular Human Reproduction 16 3-13. (doi:10.1093/molehr/gap059)

Aitken RJ, De Iuliis GN, Finnie JM, Hedges A \& McLachlan RI 2010 Analysis of the relationships between oxidative stress, DNA damage and sperm vitality in a patient population: development of diagnostic criteria. Human Reproduction 25 2415-2426. (doi:10.1093/humrep/ deq214)

Aitken RJ, Iones KT \& Robertson SA 2012 Reactive oxygen species and sperm function-in sickness and in health. Journal of Andrology 33 1096-1104. (doi:10.2164/jandrol.112.016535)

Alvarez JG, Touchstone JC, Blasco L \& Storey BT 1987 Spontaneous lipid peroxidation and production of hydrogen peroxide and superoxide in human spermatozoa. Journal of Andrology 8 338-348. (doi:10.1002/j.1939-4640.1987.tb00973.x)

Amaral A, Ramalho-Santos J \& St John JC 2007 The expression of polymerase gamma and mitochondrial transcription factor $\mathrm{A}$ and the regulation of mitochondrial DNA content in mature human sperm. Human Reproduction 22 1585-1596. (doi:10.1093/humrep/dem030)

Bahr GF \& Engler WF 1970 Considerations of volume, mass, DNA, and arrangement of mitochondria in the midpiece of bull spermatozoa. Experimental Cell Research 60 338-340. (doi:10.1016/00144827(70)90526-4)

Biggers JD, Whitten WK \& Whittingham DG 1971 The culture of mouse embryos in vitro. In Methods of Mammalian Embryology, pp 86-116. Ed JC Daniel. San Francisco, CA, USA: WH Freeman Press.

Bruijn MH, Coulson AR, Drouin J, Eperon JC, Nierlich DP, Rpe BA \& Sanger F 1981 Sequence and organization of the human mitochondrial genome. Nature 290 457-465. (doi:10.1038/290457a0)

Calogero AE, Fishel S, Hall J, Ferrara E, Vicari E, Greeen S, Hunter A, Burrello N, Thornton S \& D'Agata R 1998 Correlation between intracellular cAMP content, kinematic parameters and hyperactivation of human spermatozoa after incubation with pentoxifylline. Human Reproduction 13 911-915. (doi:10.1093/humrep/13.4.911)

D'Agata R, Vicari E, Moncada ML, Sidoti G, Calogero AE, Fornito MC, Minacapilli G, Mongioi A \& Polosa P 1990 Generation of reactive oxygen species in subgroups of infertile men. International Journal of Andrology 13 344-351. (doi:10.1111/j.1365-2605.1990.tb01042.x)

De Iuliis GN, Thomson LK, Mitchell LA, Finnie JM, Koppers AJ, Hedges A, Nixon B \& Aitken RJ 2009 DNA damage in human spermatozoa is highly correlated with efficiency of chromatin remodeling and the formation of 8-hydroxy-2'-deoxyguanosine, a marker of oxidative stress. Biology of Reproduction 81 517-524. (doi:10.1095/biolreprod.109.076836)

de Lamirande E \& Gagnon C 1992 Reactive oxygen species and human spermatozoa. Effects on the motility of intact spermatozoa and on sperm axonemes. Journal of Andrology 13 368-378.

Diez-Sanchez C, Ruiz-Pesini E, Lapena AC, Montoya J, Perez-Martos A, Enriquez JA \& Lopez-Perez MJ 2003 Mitochondrial DNA content of human spermatozoa. Biology of Reproduction 68 180-185. (doi:10.1095/biolreprod.102.005140)

Erkkilä K, Pentikäinen V, Wikström M, Parvinen M \& Dunkel L 1999 Partial oxygen pressure and mitochondrial permeability transition affect germ cell apoptosis in the human testis. Journal of Clinical Endocrinology and Metabolism 4 4253-4259. (doi:10.1210/jc.84.11.4253)

Folgero T, Bertheussen K, Lindal S, Torbergsen T \& Oian P 1993 Mitochondrial disease and reduced sperm motility. Human Reproduction 8 1863-1868.

Ford WCL 1990 The role of oxygen free radicals in the pathology of human spermatozoa: implications for IVF. Clinical IVF forum. In Clinical IVF Forum. Current Views in Assisted Reproduction, pp 123-139. Eds PL Matson \& BA Libermann. Manchester University Press, Manchester, UK.
Gabriel MS, Chan SW, Alhathal N, Chen JZ \& Zini A 2012 Influence of microsurgical varicocelectomy on human sperm mitochondrial DNA copy number: a pilot study. Journal of Assisted Reproduction and Genetics 29 759-764. (doi:10.1007/s10815-012-9785-z)

Hecht NB \& Liem H 1984 Mitochondrial DNA is synthesized during meiosis and spermiogenesis in the mouse. Experimental Cell Research 154 293-298. (doi:10.1016/0014-4827(84)90688-8)

Henkel R, Kierspel E, Stalf T, Mehnert C, Menkveld R, Tinneberg HR, Schill WB \& Kruger TF 2005 Effect of reactive oxygen species produced by spermatozoa and leukocytes on sperm functions in non-leukocytospermic patients. Fertility and Sterility 83 635-642. (doi:10.1016/j.fertnstert.2004.11.022)

Hughes LM, Griffith R, Carey A, Butler T, Donne SW, Beagley KW \& Aitken RJ 2009 The spermostatic and microbicidal actions of quinones and maleimides: toward a dual-purpose contraceptive agent. Molecular Pharmacology 76 113-124. (doi:10.1124/mol.108.053645)

Kao S, Chao HT \& Wei YH 1995 Mitochondrial deoxyribonucleic acid 4977-bp deletion is associated with diminished fertility and motility of human sperm. Biology of Reproduction 52 729-736. (doi:10.1095/ biolreprod52.4.729)

Kao SH, Chao HT \& Wei YH 1998 Multiple deletions of mitochondrial DNA are associated with the decline of motility and fertility of human spermatozoa. Molecular Human Reproduction 4 657-666. (doi:10.1093/ molehr/4.7.657)

Kao SH, Chao HT, Chen HW, Hwang TJS, Liao TL \& Wei YH 2008 Increase of oxidative stress in human sperm with lower motility. Fertility and Sterility 89 1183-1190. (doi:10.1016/j.fertnstert.2007.05.029)

Kasai T, Ogawa K, Mizuno K, Nagai S, Uchida Y, Ohta S, Fujie M, Suzuki K, Hirata S \& Hoshi K 2002 Relationship between sperm mitochondrial membrane potential, sperm motility, and fertility potential. Asian Journal of Andrology 4 97-103.

Koppers AJ, De Juliis GN, Finnie JM, McLaughlin EA \& Aitken RJ 2008 Significance of mitochondrial reactive oxygen species in the generation of oxidative stress in spermatozoa. Journal Clinical Endocrinology and Metabolism 93 3199-3207. (doi:10.1210/jc.2007-2616)

Krausz C, West K, Buckingham D \& Aitken RJ 1992 Development of a technique for monitoring the contamination of human semen samples with leucocytes. Fertility and Sterility 57 1317-1325. (doi:10.1016/ S0015-0282(16)55094-8)

Krausz C, Mills C, Rogers S, Tan SL \& Aitken RJ 1994 Stimulation of oxidant generation by human sperm suspensions using phorbol esters and formyl peptides: relationships with motility and fertilization in vitro. Fertility and Sterility 62 599-605. (doi:10.1016/S0015-0282(16)56952-0)

Lee HC, Yin PH, Lu CY, Chi CW \& We YH 2000 Increase of mitochondria and mitochondrial DNA in response to oxidative stress in human cell. Journal of Biochemistry 348 (part 2) 425-432. (doi:10.1042/bj3480425)

Lestienne $\mathbf{P}$, Reynier $\mathbf{P}$, Chretien MF, Pennisson-Besnier I, Malthiery $\mathbf{Y}$ \& Rohmer V 1997 Oligoasthenospermia associated with multiple mitochondrial DNA rearrangements. Molecular Human Reproduction 3 811-814. (doi:10.1093/molehr/3.9.811)

Liu CS, Tsai CS, Kuo CL, Chen HW, Lii CK, Ma YS \& Wei YH 2003 Oxidative stress-related alteration of the copy number of mitochondrial DNA in human leukocytes. Free Radical Research 37 1307-1317. (doi:10.1080/10715760310001621342)

Luo Y, Liao W, Chen Y, Cui J, Liu F, Jiang C, Gao W \& Gao Y 2011 Altitude can alter the mtDNA copy number and DNA integrity in sperm. Journal of Assisted Reproduction and Genetics 28 951-956. (doi:10.1007/ s10815-011-9620-y)

Marchetti C, Jouy N, Leroy-Martin B, Defossez A, Formstecher P \& Marchetti P 2004 Comparison of four fluorochromes for the detection of the inner mithocondrial membrane potential in human spermatozoa and their correlation with sperm motility. Human Reproduction 19 2267-2276. (doi:10.1093/humrep/deh416)

May-Panloup $P$, Chrètien MF, Savagner $F$, Vasseur $C$, Jean $M$, Malthièry $Y$ \& Reynier P 2003 Increased sperm mitochondrial content in male infertility. Human Reproduction 18 550-556. (doi:10.1093/humrep/ deg096)

Mitchell LA, De Iuliis GN \& Aitken RJ 2011 The Tunnel consistently underestimates DNA damage in human spermatozoa and is influenced by DNA compaction and cell vitality: development of an improved methodology. International Journal of Andrology 34 2-13. (doi:10.1111/ j.1365-2605.2009.01042.x) 
Muratori M, Piomboni P, Baldi E, Filimberti E, Pecchioli P, Moretti E, Gambera L, Baccetti B, Biagiotti R, Forti G et al. 2000 Functional and ultrastructural features of DNA-fragmented human sperm. Journal of Andrology 21 903-912.

Narisawa S, Hecht NB, Goldberg E, Boatright KM, Reed JC \& Millán JL 2002 Testis-specific cytochrome c-null mice produce functional sperm but undergo early testicular atrophy. Molecular and Cellular Biology 22 5554-5562. (doi:10.1128/MCB.22.15.5554-5562.2002)

Pasqualotto FF, Sharma RK, Nelson DR, Thomas AJ \& Agarwal A 2000 Relationship between oxidative stress, semen characteristics, and clinical diagnosis in men undergoing infertility investigation. Fertility and Sterility 73 459-464. (doi:10.1016/S0015-0282(99)00567-1)

Perdichizzi A, Nicoletti F, La Vignera S, Barone N, D'Agata R, Vicari E \& Calogero AE 2007 Effects of tumor necrosis factor- $\alpha$ on human sperm motility and apoptosis. Journal of Clinical Immunology 27 152-162. (doi:10.1007/s10875-007-9071-5)

Rossato M, La Sala GB, Balasini M, Taricco F, Galeazzi C, Ferlin A \& Foresta C 1999 Sperm treatment with extracellular ATP increases fertilization rates in in-vitro fertilization for male factor infertility. Human Reproduction 14 694-697. (doi:10.1093/humrep/14.3.694)

Ruiz-Pesini E, Lapena AC, Diez-Sanchez C, Perez-Martos A, Montoya J, Alvarez E, Diaz M, Urries A, Montoro L, Lopez-Perez MJ et al. 2000 Human mtDNA haplogroups associated with high or reduced spermatozoa motility. American Journal of Human Genetics 67 682-696. (doi:10.1086/303040)

Sakkas D, Seli E, Bizzaro D, Tarozzi N \& Manicardi GC 2003 Abnormal spermatozoa in the ejaculate: abortive apoptosis and faulty nuclear remodeling during spermatogenesis. Reproductive Biomedicine Online 7 428-432. (doi:10.1016/S1472-6483(10)61886-X)

Salehi MH, Houshmand M, Bidmeshkipour A, Shariat S \& Panahi SS M 2006 Low sperm motility due to mitochondrial DNA multiple deletions. Journal of Chinese Clinical Medicine 9 181-185.

Sawyer DE, Mercer BG, Wiklendt AM \& Aitken RJ 2003 Quantitative analysis of gene-specific DNA damage in human spermatozoa. Mutation Research 529 21-34. (doi:10.1016/S0027-5107(03)00101-5)

Shamsi MB, Venkatesh S, Tanwar M, Sharma RK, Dhawan A, Kumar R, Gupta NP, Malhotra N, Singh N, Mittal S et al. 2009 DNA integrity and semen quality in men with low seminal antioxidant levels. Mutation Research 665 29-36. (doi:10.1016/j.mrfmmm.2009.02.017)

Song G \& Lewis V 2008 Mitochondrial DNA integrity and copy number in sperm from infertile men. Fertility and Sterility 90 2238-2244. (doi:10.1016/j.fertnstert.2007.10.059)

St John JC, Cooke ID \& Barratt CLR 1997 Mitochondrial mutations and male infertility. Nature Medicine 3 124-125. (doi:10.1038/nm0297125a)

St John JC, Sakkas D \& Barratt CLR 2000 A role for mitochondrial DNA and sperm survival. Journal of Andrology 21 189-199. (doi:10.1002/j.1939-4640.2000.tb02093.x)

Susin SA, Lorenzo HK, Zamzami N, Marzo I, Snow BE, Brothers GM, Mangion J, Jacotot E, Costantini P, Loeffler M et al. 1999 Molecular characterization of mitochondrial apoptosis-inducing factors. Nature 397 441-446. (doi:10.1038/17135)
Tesarik J, Mendoza C \& Greco E 2002 Paternal effects acting during the first cycle of human preimplantation development after ICSI. Human Reproduction 1 189-202.

Troiano L, Granata AR, Cossarizza A, Kalashnikova G, Bianchi R, Pini G, Tropea F, Carani C \& Franceschi C 1998 Mitochondrial membrane potential and DNA stainability in human sperm cells: a flow cytometry analysis with implications for male infertility. Experimental Cell Research 241 384-393. (doi:10.1006/excr.1998.4064)

Varum S, Bento C, Sousa AP, Gomes-Santos CS, Henriques P, AlmeidaSantos T, Teodósio C, Paiva A \& Ramalho-Santos J 2007 Characterization of human sperm population using conventional parameters, surface ubiquitination and apoptotic markers. Fertility and Sterility 87 572-583. (doi:10.1016/j.fertnstert.2006.07.1528)

Venkatesh S, Deecaraman M, Kumar R, Shamsi MB \& Dada R 2009 Role of reactive oxygen species in the pathogenesis of mitochondrial DNA(mtDNA) mutations in male infertility. Indian Journal of Medical Research 129 127-137.

Wang X, Sharma RK, Gupta A, George V, Thomas AJ, Falcone T \& Agarwal A 2003 Alterations in mitochondria membrane potential and oxidative stress in men: a prospective observational study. Fertility and Sterility 80 844-850. (doi:10.1016/S0015-0282(03)00983-X)

Whittington K \& Ford VCL 1999 Relative contribution of leukocytes and of spermatozoa to reactive oxygen species production in human sperm suspensions. International Journal of Andrology 22 229-235. (doi:10.1046/j.1365-2605.1999.00173.x)

Whittington K, Harrison SC, Williams KM, Day JL, Maclaughlin EA, Hull MGR \& Ford VCL 1999 Reactive oxygen species (ROS) production and the outcome of diagnostic tests of sperm function. International Journal of Andrology 22 236-242. (doi:10.1046/j.13652605.1999.00174.x)

World Health Organization 2010 WHO Laboratory Manual for the Examination of Human Semen, 5th edn. Geneva, Switzerland: WHO Library Cataloguing-in-Publication Data.

Yakes FM \& Van Houten B 1997 Mitochondrial DNA damage is more extensive and persists longer than nuclear DNA damage in human cells following oxidative stress. PNAS 94 514-519. (doi:10.1073/ pnas.94.2.514)

Zidi-Jrah I, Hajlaoui A, Mougou-Zerelli S, Kammoun M, Meniaaoui I, Dallem A, Brahem S, Fekih M, Bibi M, Saad A et al. 2016 Relationship between sperm aneuploidy, sperm DNA integrity, chromatin packaging, traditional semen parameters, and recurrent pregnancy loss. Fertility and Sterility 105 58-65. (doi:10.1016/j.fertnstert.2015.09.041)

Received 27 June 2016

First decision 29 July 2016

Revised manuscript received 11 September 2016

Accepted 19 September 2016 